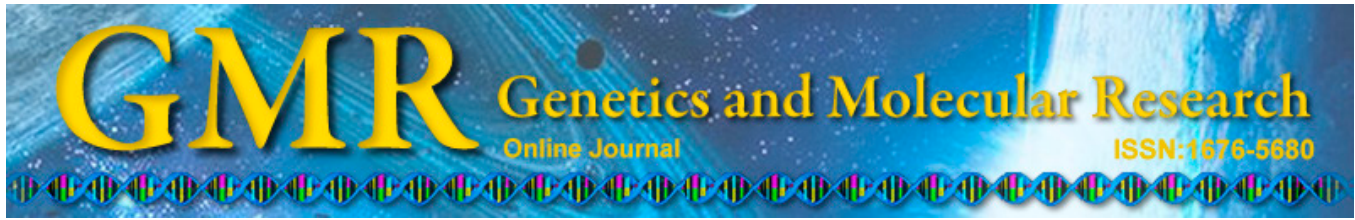

\title{
Meta-analysis demonstrates no association between XRCC1 Arg399GIn polymorphism and bladder cancer risk
}

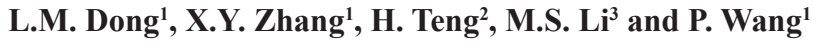 \\ ${ }^{1}$ Department of Urological Surgery, \\ The Fourth Affiliated Hospital of China Medical University, Shenyang, China \\ ${ }^{2}$ Department of Neurosurgery, \\ The Shengjing Affiliated Hospital of China Medical University, Shenyang, China \\ ${ }^{3}$ Department of Emergency Surgery, \\ The Fourth Affiliated Hospital of China Medical University, Shenyang, China \\ Corresponding author: P. Wang \\ E-mail: cmu4h_wp@126.com
}

Genet. Mol. Res. 13 (4): 9976-9985 (2014)

Received September 17, 2013

Accepted January 13, 2014

Published November 28, 2014

DOI http://dx.doi.org/10.4238/2014.November.28.2

\begin{abstract}
We examined whether the X-ray repair crosscomplementing group 1 (XRCC1) Arg399Gln polymorphism is a risk factor for bladder cancer by conducting a meta-analysis. We searched the Pubmed and Embase databases for study retrieval. This meta-analysis examined 16 case-control studies, including 892 prostate cancer cases and 1020 healthy controls. Meta-analysis results based on these studies showed no significant association between the XRCC1 Arg399Gln polymorphism and bladder cancer risk in comparisons of the glutamine (Gln) allele vs arginine (Arg) allele, Arg/Arg vs (Gln/Gln + Gln/Arg), Gln/Gln vs (Gln/Arg + Arg/Arg), Gln/Gln vs Arg/Arg, and Gln/Arg vs Arg/Arg [odds ratio $(\mathrm{OR})=0.96,95 \%$ confidence interval $(\mathrm{CI})=0.80$ $1.16, \mathrm{P}=0.70 ; \mathrm{OR}=1.13,95 \% \mathrm{CI}=0.70-1.82, \mathrm{P}=0.62 ; \mathrm{OR}=0.92$, $95 \% \mathrm{CI}=0.79-1.07, \mathrm{P}=0.29 ; \mathrm{OR}=0.90,95 \% \mathrm{CI}=0.69-1.16, \mathrm{P}=0.42$; $\mathrm{OR}=0.89,95 \% \mathrm{CI}=0.75-1.05, \mathrm{P}=0.17$, respectively]. In subgroup
\end{abstract}


analysis by ethnicity, no association was observed between the XRCC1 Arg399Gln polymorphism and bladder cancer risk in Caucasian, Mongoloid, or black populations. We identified no association between the XRCC1 Arg399Gln polymorphism and bladder cancer risk.

Key words: Bladder cancer; XRCC1 Arg399Gln; Gene polymorphism; Meta-analysis

\section{INTRODUCTION}

Bladder cancer is one of the most common tumors and is the eighth leading cause of cancer death among people in the USA (Siegel et al., 2012). In 2012, bladder cancer accounted for $4.49 \%(73,510)$ of all newly diagnosed cancers and $2.58 \%(14,880)$ of all deaths in the United States. Although numerous studies have been conducted to understand bladder cancer, the detailed etiology remains largely unknown. Bladder carcinogenesis is a complex, multistep, and multifactor process, in which many factors are implicated. Smoking, exposure to industrially related aromatic amines, and uptake of drugs such as phenacetine, chlornaphrazine, and cyclophosphamide are the only established risk factors (Steineck et al., 1995; Cohen et al., 2000). Many studies have suggested that genetic factors play an important role in the etiology of bladder cancer (Mattulo et al., 2005; Andrew et al., 2006). DNA damage by carcinogens and failure to accurately repair DNA following mutations are related to carcinogenesis (Sak et al., 2007).

The human X-ray repair cross-complementing group 1 (XRCC1) gene is located on chromosome $19 \mathrm{q} 13.2-13.3$ and is $33 \mathrm{~kb}$ in length. As a scaffold protein closely associated with the base excision repair (BER) pathway, the predominant DNA damage repair pathway for processing small base lesions derived from oxidation and alkylation damage, XRCC1 interacts with most components of the BER short-patch pathway (Vidal et al., 2001; Campalans et al., 2005; Das et al., 2006). Arg399Gln (exon 10, rs25487 in dbSNP, G/A, arginine to glutamine) is a common polymorphism of XRCC1. The XRCC1 Arg399Gln variant is related to DNA repair based on its location in the $\mathrm{COOH}$-terminal side of the poly (ADP ribose) polymerase-interacting domain within a relatively non-conserved region between conserved residues of the breast cancer $1 \mathrm{C}$-terminal domain; this indicates that the protein-protein interaction module in many proteins is involved in DNA repair (Masson et al., 1998). In addition, higher levels of sister chromatid exchange (Abdel-Rahman and El-Zein, 2000), aflatoxin B1-DNA adducts, glycophorin A mutations (Lunn et al., 1999), and polyphenol DNA adducts (Duell et al., 2000) may be related to the variant.

Several studies have been performed to elucidate the effect of the XRCC1 Arg399Gln polymorphism on bladder cancer susceptibility. However, the results are inconsistent. The aim of this meta-analysis was to investigate the association between the XRCC1 Arg399Gln polymorphism and bladder cancer risk by examining all eligible case-control studies published to date.

\section{MATERIAL AND METHODS}

\section{Literature search strategy}

Pubmed and Embase database searches were performed to retrieve articles regarding 
the XRCC1 Arg399Gln polymorphism and bladder cancer risk up to May 2013 without language restrictions and using the following key words: "XRCC1", "X-ray repair cross-complementing group 1", "polymorphism", and "bladder cancer". The search included only research on human subjects. References including major textbooks, review articles, and included articles were also identified through manual searches to find potentially eligible studies.

\section{Inclusion and exclusion criteria}

For inclusion in this meta-analysis, the following criteria were established: 1) casecontrol study addressed bladder cancer cases and controls; 2) study evaluated the association between the XRCC1 Arg399Gln polymorphism and bladder cancer risk; and 3) study included sufficient genotype data for extraction. Studies that were excluded included: 1) non-case-control studies evaluating the association between the XRCC1 Arg399Gln polymorphism and bladder cancer risk; and 2) studies based on incomplete raw data with no usable data reported.

\section{Data extraction}

Using a standardized form, 2 reviewers independently extracted data from published studies. The following information was extracted from included articles: first author, year of publication, country, ethnicity, study design, source of controls, number of cases and controls, detection methods, allele and genotypes frequency of the polymorphism, and evidence of Hardy-Weinberg equilibrium in controls. Agreement was reached after discussion among the authors to resolve conflicting evaluations.

\section{Statistical analysis}

The overall association between the XRCC1 Arg399Gln polymorphism and bladder cancer was calculated by individual or pooled odds ratios (ORs) and $95 \%$ confidence intervals (CIs) using Review Manager Version 5.0.25 (provided by The Cochrane Collaboration, available at: http://www.cc-ims.net/revman) and STATA package version 12.0 (Stata Corporation; College Station, TX, USA). We evaluated the following contrasts for the XRCC1 Arg399Gln polymorphism: comparison of the variant allele with the wild-type allele (Gln allele vs Arg allele); comparison of the variant homozygote with the wild-type homozygote and the heterozygote (Gln/Gln $v s$ Gln/Arg + Arg/Arg); comparison of the wild-type homozygote with the variant homozygote and the heterozygote (Arg/Arg vs Gln/Arg + Gln/Gln); and comparison of the variant homozygote with the heterozygote and wild-type homozygote (Gln/Gln $v s$ Arg/ $\mathrm{Arg}$; Gln/Gln vs Gln/Arg). Cochran's Q statistic was used to estimate variations and heterogeneities between studies (Higgins and Thompson, 2002; Zintzaras and Ioannidis, 2005). When a significant $\mathrm{Q}$-statistic $(\mathrm{P}<0.05)$ indicated heterogeneity across studies, the random effects model was used for meta-analysis; otherwise, the fixed effects model was used (Viechtbauer, 2007). Hardy-Weinberg equilibrium in genotype frequencies of controls was calculated using the chi-square test. To determine and explain the diversity among the results of different studies, subgroup analysis was performed. Sensitivity analysis was mainly performed by sequential omission of individual studies. Publication bias was assessed by Begg's funnel plot, and funnel plot asymmetry was assessed based on Egger's linear regression test (Peters et al., 2006). P values from Egger's test $<0.05$ are considered to be statistically significant. All 
$\mathrm{P}$ values were 2-sided. To ensure the reliability and the accuracy of the results, 2 reviewers (L.M.D. and M.S.L.) independently input data into the statistics software programs and both researchers obtained the same results.

\section{RESULTS}

\section{Studies included in the meta-analysis}

The search strategy retrieved 46 potentially relevant papers. According to the inclusion criteria, 21 studies were included in this meta-analysis. These 21 selected case-control studies (Stern et al., 2001; Shen et al., 2003; Kelsey et al., 2004; Sanyal et al., 2004; Broberg et al., 2005; Andrew et al., 2006; Karahalil et al., 2006; Matullo et al., 2001, 2005, 2006; Figueroa et al., 2007; Huang et al., 2007; Sak et al., 2007; Andrew et al., 2008; Arizono et al., 2008; Fontana et al., 2008; Wen et al., 2009; Gao et al., 2010; Wang et al., 2010; Mittal et al., 2012; Zhi et al., 2012) included 5759 bladder cancer cases and 6521 controls. All studies were case-control studies that evaluated the association between the XRCC1 Arg399Gln polymorphism and bladder cancer risk. All articles were written in English. The Hardy-Weinberg equilibrium test was performed to determine the genotype distribution of the controls in all studies included. All of the studies except for 5 conformed to Hardy-Weinberg equilibrium; 3 studies (Kelsey et al., 2004; Andrew et al., 2006, 2008) were not in Hardy-Weinberg equilibrium, and 2 studies (Huang et al., 2007; Wen et al., 2009) lacked sufficient data for calculating the $\mathrm{P}$ value to determine Hardy-Weinberg equilibrium.

The study characteristics are summarized in Table 1. The genotype distribution and risk allele frequency of the studies included are summarized in Table 2. A summary of the meta-analysis findings of the association between the XRCC1 Arg399Gln polymorphism and bladder cancer risk is shown in Table 3.

Table 1. Baseline characteristics of studies included in the meta-analysis.

\begin{tabular}{|c|c|c|c|c|c|c|}
\hline \multirow[t]{2}{*}{ First author } & \multirow[t]{2}{*}{ Country } & \multirow[t]{2}{*}{ Ethnicity } & \multirow[t]{2}{*}{ Source of controls } & \multicolumn{2}{|c|}{ No. of subjects } & \multirow[t]{2}{*}{ Method } \\
\hline & & & & Cases & Controls & \\
\hline Matullo et al. (2001) & Italy & Caucasian & Hospital-based & 124 & 84 & PCR-RFLP \\
\hline Stern et al. (2001) & USA & Caucasian and black & Hospital-based & $233(215 / 19)^{*}$ & $210(198 / 13)$ & PCR-RFLP \\
\hline Shen et al. (2003) & Italy & Caucasian & Hospital-based & 201 & 214 & PCR-RFLP \\
\hline Kelsey et al. (2004) & USA & Mixed & Population- based & 355 & 544 & PCR-RFLP \\
\hline Sanyal et al. (2004) & Germany & Caucasian & Population-based & 311 & 246 & PCR-RFLP \\
\hline Broberg et al. (2005) & Sweden & Caucasian & Population-based & 61 & 155 & Sequenom \\
\hline Matullo et al. (2005) & Italy & Caucasian & Hospital-based & 311 & 312 & PCR-RFLP/Taqman \\
\hline Andrew et al. (2006) & USA & Mixed & Population-based & 306 & 538 & PCR-RFLP \\
\hline Karahalil et al. (2006) & Turkey & Caucasian & Population-based & 100 & 100 & PCR-RFLP \\
\hline Matullo et al. (2006) & Mixed & Caucasian & Population-based & 124 & 1094 & PCR-RFLP/DHPLC/TaqMan \\
\hline Sak et al. (2007) & UK & Mixed & $\begin{array}{l}\text { Population- and } \\
\text { Hospital-based }\end{array}$ & 532 & 560 & Taqman \\
\hline Figueroa et al. (2007) & Spain & Caucasian & Hospital-based & 1061 & 101 & Taqman \\
\hline Fontana et al. (2008) & France & Caucasian & Hospital-based & 51 & 45 & Taqman \\
\hline Arizono et al. (2008) & Japan & Mongoloid & Hospital-based & 251 & 251 & PCR-RFLP \\
\hline Andrew et al. (2008) & USA & Mixed & $\begin{array}{l}\text { Population- and } \\
\text { Hospital-based }\end{array}$ & 990 & 1253 & PCR-RFLP/Taqman \\
\hline Wang et al. (2010) & China & Mongoloid & Hospital-based & 234 & 253 & PCR-RFLP \\
\hline Mittal et al. (2012) & India & Mongoloid & Population-based & 212 & 250 & PCR-RFLP \\
\hline Zhi et al. (2012) & China & Mongoloid & Population-based & 302 & 311 & PCR-RFLP \\
\hline
\end{tabular}

*Represents Caucasians and blacks. 
Table 2. Genotype distribution and risk allele frequency in all studies included.

\begin{tabular}{|c|c|c|c|c|c|c|c|c|}
\hline \multirow[t]{2}{*}{ First author } & \multicolumn{3}{|c|}{ Cases } & \multicolumn{3}{|c|}{ Controls } & \multicolumn{2}{|c|}{ HWE test } \\
\hline & Arg/Arg & Gln/Arg & $\mathrm{Gln} / \mathrm{Gln}$ & Arg/Arg & Gln/Arg & Gln/Gln & $\chi^{2}$ & $\mathrm{P}$ \\
\hline Matullo et al. (2001) & 53 & 58 & 13 & 31 & 41 & 12 & 0.07 & 0.79 \\
\hline Stern et al. (2001) & $96(87 / 9)^{*}$ & $116(106 / 10)$ & $21(21 / 0)$ & $88(79 / 9)$ & $96(92 / 4)$ & $26(26 / 0)$ & 0.00 & 0.98 \\
\hline Shen et al. (2003) & 93 & 87 & 21 & 92 & 98 & 24 & 0.08 & 0.78 \\
\hline Kelsey et al. (2004) & 132 & 187 & 36 & 228 & 230 & 86 & 4.66 & 0.03 \\
\hline Sanyal et al. (2004) & 124 & 155 & 32 & 113 & 110 & 23 & 0.26 & 0.61 \\
\hline Broberg et al. (2005) & 26 & 31 & 4 & 80 & 62 & 13 & 0.04 & 0.84 \\
\hline Matullo et al. (2005) & 136 & 135 & 40 & 120 & 145 & 47 & 0.09 & 0.77 \\
\hline Andrew et al. (2006) & 118 & 155 & 33 & 225 & 227 & 86 & 4.93 & 0.03 \\
\hline Karahalil et al. (2006) & 49 & 38 & 13 & 41 & 42 & 17 & 1.18 & 0.28 \\
\hline Matullo et al. (2006) & 54 & 53 & 17 & 484 & 482 & 128 & 0.23 & 0.63 \\
\hline Sak et al. (2007) & 218 & 248 & 66 & 226 & 259 & 75 & 0.00 & 0.95 \\
\hline Figueroa et al. (2007) & 434 & 494 & 133 & 41 & 47 & 13 & 0.01 & 0.93 \\
\hline Fontana et al. (2008) & 21 & 25 & 5 & 18 & 18 & 9 & 1.25 & 0.26 \\
\hline Arizono et al. (2008) & 139 & 102 & 10 & 140 & 90 & 21 & 1.41 & 0.24 \\
\hline Andrew et al. (2008) & 412 & 456 & 122 & 533 & 536 & 184 & 6.59 & 0.01 \\
\hline Wang et al. (2010) & 113 & 102 & 19 & 105 & 126 & 22 & 3.41 & 0.06 \\
\hline Mittal et al. (2012) & 67 & 106 & 39 & 102 & 109 & 39 & 1.19 & 0.28 \\
\hline Zhi et al. (2012) & 121 & 151 & 30 & 148 & 143 & 20 & 3.57 & 0.06 \\
\hline
\end{tabular}

*Represents Caucasians and blacks separately.

Table 3. Meta-analysis of the association between the XRCC1 Arg399Gln polymorphism and bladder cancer risk.

\begin{tabular}{|c|c|c|c|c|c|}
\hline \multirow[t]{2}{*}{ Contrast } & \multirow[t]{2}{*}{ Random effects OR $(95 \% \mathrm{CI})$} & \multirow[t]{2}{*}{ Fixed effects OR $(95 \% \mathrm{CI})$} & \multicolumn{2}{|c|}{ Heterogeneity } & \multirow[t]{2}{*}{$P$ value for $Z$-tes } \\
\hline & & & $P$ value & $\mathrm{I}^{2}$ & \\
\hline Gln allele $v s$ Arg allele & $0.96(0.80,1.16)$ & & $<0.00001$ & $77 \%$ & 0.70 \\
\hline Caucasian & $0.87(0.72,1.07)$ & & 0.004 & $63 \%$ & 0.19 \\
\hline Mongoloid & $1.21(0.74,1.99)$ & & $<0.00001$ & $90 \%$ & 0.44 \\
\hline Black & $2.50(0.66,9.46)$ & & & & 0.18 \\
\hline Mixed & $0.92(0.75,1.14)$ & & & & 0.46 \\
\hline $\operatorname{Arg} / \operatorname{Arg} v s(\mathrm{Gln} / \mathrm{Gln}+\mathrm{Gln} / \mathrm{Arg})$ & $1.13(0.70,1.82)$ & & $<0.00001$ & $88 \%$ & 0.62 \\
\hline Caucasian & $1.33(0.82,2.15)$ & & $<0.00001$ & $79 \%$ & 0.25 \\
\hline Mongoloid & $0.75(0.14,4.16)$ & & $<0.00001$ & $96 \%$ & 0.74 \\
\hline Mixed & $1.09(0.78,1.51)$ & & & & 0.63 \\
\hline $\mathrm{Gln} / \mathrm{Gln} v s(\mathrm{Gln} / \mathrm{Arg}+\mathrm{Arg} / \mathrm{Arg})$ & & $0.92(0.79,1.07)$ & 0.32 & $12 \%$ & 0.29 \\
\hline Caucasian & & $0.86(0.70,1.06)$ & 0.73 & $0 \%$ & 0.16 \\
\hline Mongoloid & $1.01(0.61,1.69)$ & & 0.04 & $64 \%$ & 0.96 \\
\hline Mixed & $0.90(0.63,1.29)$ & & & & 0.57 \\
\hline Gln/Gln vs Arg/Arg & $0.90(0.69,1.16)$ & & 0.010 & $52 \%$ & 0.42 \\
\hline Caucasian & & $0.86(0.70,1.06)$ & 0.34 & $11 \%$ & 0.08 \\
\hline Mongoloid & $1.15(0.54,2.45)$ & & 0.002 & $80 \%$ & 0.71 \\
\hline Mixed & $0.87(0.59,1.30)$ & & & & 0.51 \\
\hline Gln/Arg vs Arg/Arg & & $0.89(0.75,1.05)$ & 0.32 & $12 \%$ & 0.17 \\
\hline Caucasian & & $0.88(0.70,1.10)$ & 0.71 & $0 \%$ & 0.27 \\
\hline Mongoloid & $0.93(0.54,1.59)$ & & 0.05 & $62 \%$ & 0.79 \\
\hline Mixed & $0.87(0.59,1.30)$ & & & & 0.51 \\
\hline
\end{tabular}

$\mathrm{OR}=$ odds ratio $; 95 \% \mathrm{CI}=95 \%$ confidence interval.

The meta-analysis revealed no association between the XRCC1 Arg399Gln polymorphism and bladder cancer risk in the comparisons of the Gln allele $v s$ Arg allele, Arg/Arg $v s$ (Gln/Gln + Gln/Arg), Gln/Gln vs (Gln/Arg + Arg/Arg), Gln/Gln vs Arg/Arg, and Gln/Arg vs $\operatorname{Arg} / \operatorname{Arg}(\mathrm{OR}=0.96,95 \% \mathrm{CI}=0.80-1.16, \mathrm{P}=0.70 ; \mathrm{OR}=1.13,95 \% \mathrm{CI}=0.70-1.82, \mathrm{P}=0.62$; $\mathrm{OR}=0.92,95 \% \mathrm{CI}=0.79-1.07, \mathrm{P}=0.29 ; \mathrm{OR}=0.90,95 \% \mathrm{CI}=0.69-1.16, \mathrm{P}=0.42 ; \mathrm{OR}=$ $0.89,95 \% \mathrm{CI}=0.75-1.05, \mathrm{P}=0.17$, respectively) (Figure 1). In the subgroup analysis based on ethnicity, studies were divided into Caucasian, Mongoloid, black, and mixed populations. 
No significant association was observed between the XRCC1 Arg399Gln polymorphism and bladder cancer risk in all populations for all comparisons (all $\mathrm{P}>0.05$ ).

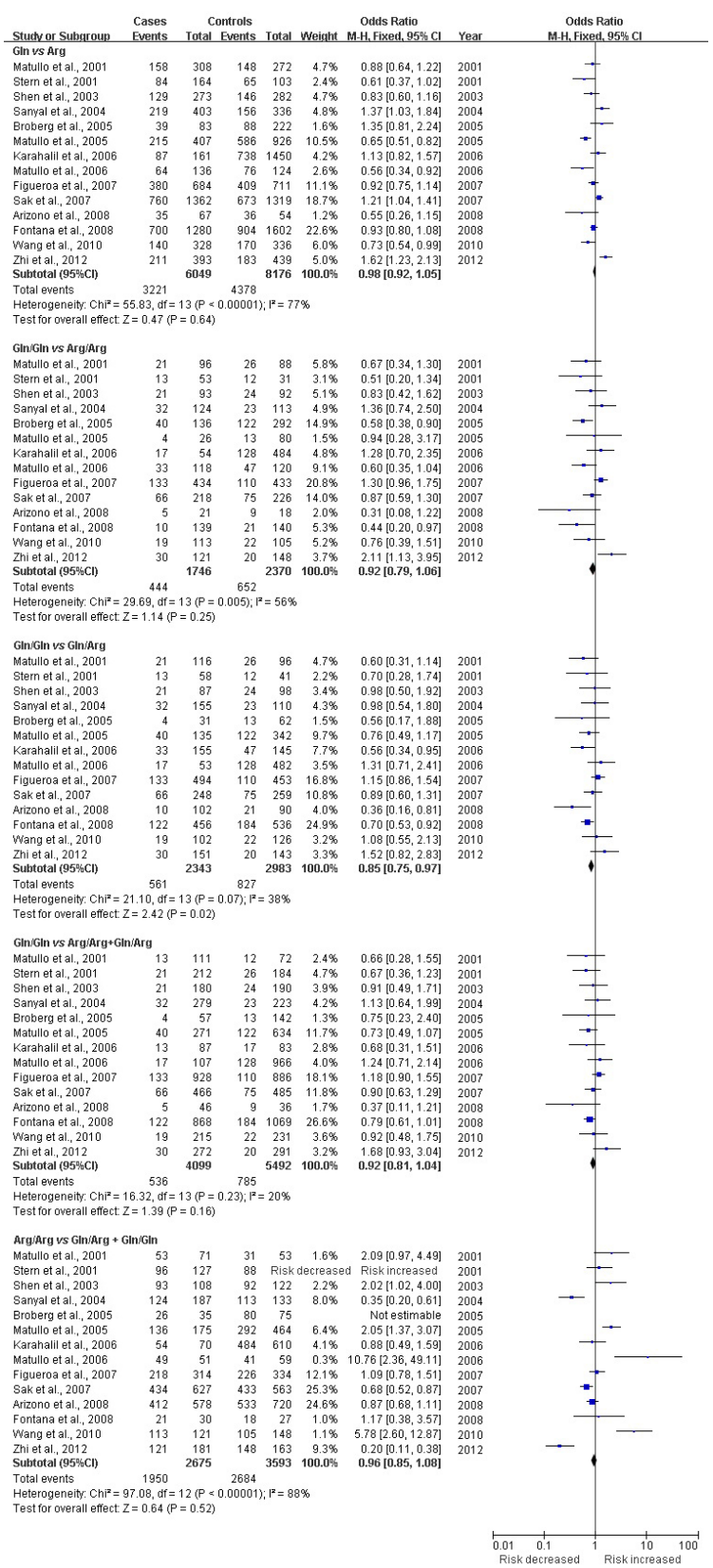

Figure 1. Forest plot of bladder cancer risk associated with the XRCC1 Arg399Gln polymorphism. Squares and horizontal lines correspond to the study-specific odds ratios (ORs) and 95\% confidence intervals (CIs). The area of the squares reflects the study-specific weight (inverse of the variance). The diamonds represent the pooled ORs and 95\% CI. M.H. = Mantel-Haenszel. 
Sensitivity analysis was performed by sequential omission of individual studies. The significance of the pooled OR in all individual and subgroup analyses was not excessively influenced by omitting any single study.

\section{Heterogeneity and publication bias}

Heterogeneity among studies was found in all comparisons of the XRCC1 Arg399Gln polymorphism; therefore, random effects model was used for single studies in the subgroup analysis to minimize the impact of bias (Table 3). Publication bias of the meta-analysis of the association between the XRCC1 Arg399Gln polymorphism and bladder cancer risk was assessed by Begg's funnel plot (Figure 2) and Egger's linear regression test. The results of all evaluations for publication bias were non-significant. The information related to Egger's publication bias test is shown in Table 4.

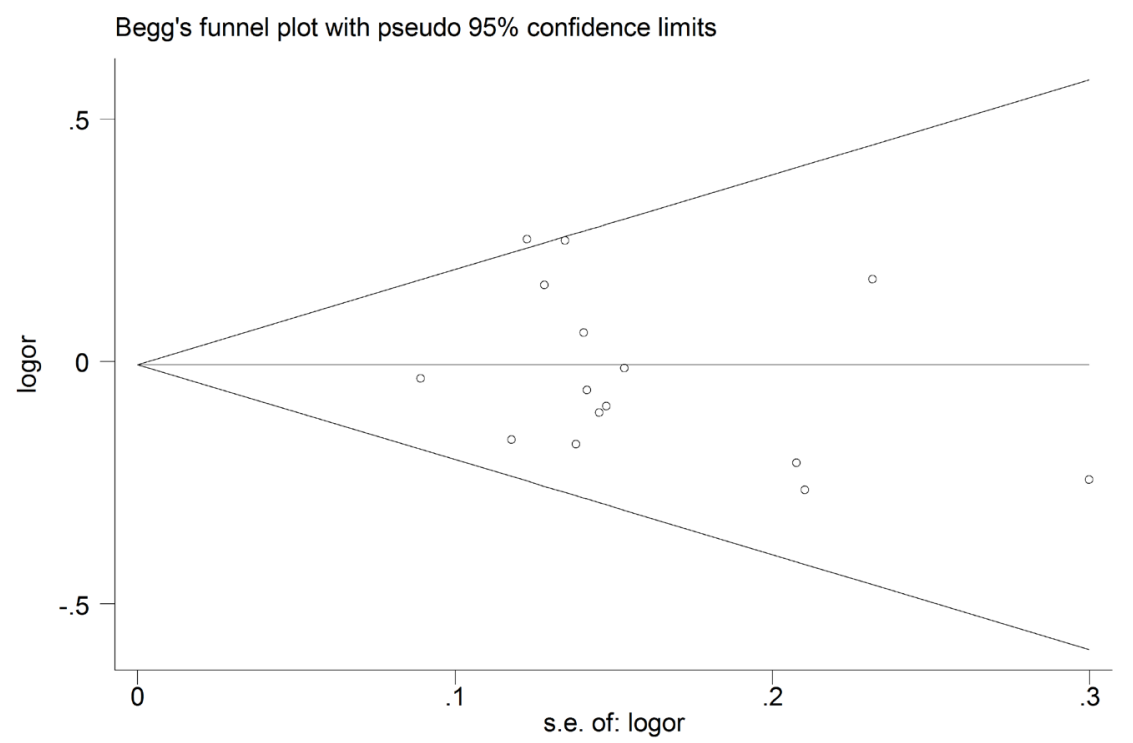

Figure 2. Begg's funnel plot of the Egger test of allele comparison for publication bias (Gln vs Arg).

Table 4. Egger's publication bias test for the XRCC1 Arg399Gln polymorphism.
\begin{tabular}{lccccc}
\hline Comparison & Coefficient & Standard error & $t$ & $\mathrm{P}>|t|$ & $95 \% \mathrm{CI}$ \\
\hline Gln allele $v s$ Arg allele & -0.91 & 1.11 & -0.82 & 0.43 & $(-3.31-1.49)$ \\
Arg/Arg $v$ (Gln/Gln $+\mathrm{Gln} / \mathrm{Arg})$ & -1.23 & 0.96 & -1.28 & 0.22 & $(-3.31-0.85)$ \\
$\mathrm{Gln} / \mathrm{Gln} v s(\mathrm{Gln} / \mathrm{Arg}+\mathrm{Arg} / \mathrm{Arg})$ & -1.39 & 0.70 & -2.00 & 0.07 & $(-2.89-0.11)$ \\
$\mathrm{Gln} / \mathrm{Gln} v s \mathrm{Arg} / \mathrm{Arg}$ & -1.36 & 0.79 & -1.73 & 0.11 & $(-3.07-0.34)$ \\
$\mathrm{Gln} / \mathrm{Arg} v s \mathrm{Arg} / \mathrm{Arg}$ & 0.28 & 1.14 & 0.24 & 0.81 & $(-2.19-2.74)$ \\
\hline
\end{tabular}

\section{DISCUSSION}

Few studies have been conducted to investigate the association between the XRCC1 Arg399Gln polymorphism and bladder cancer risk in recent decades. Stern et al. (2001) found 
a slight decrease in risk for individuals who carried the Gln/Gln genotype compared with those who had the Arg/Arg genotype; however, the difference was not statistically significant (age-, gender-, and ethnicity-adjusted $\mathrm{OR}=0.7 ; 95 \% \mathrm{CI}=0.4-1.4 ; \mathrm{P}=0.35$, for whites and blacks combined). Subsequently, Shen et al. (2003) carried out a case-control investigation in Northern Italy and found that the XRCC1 Arg399Gln polymorphism had a protective influence on bladder cancer among heavy smokers. Arizono et al. (2008) indicated that the Gln/Gln genotype had a protective effect against bladder cancer (adjusted $\mathrm{OR}=0.37,95 \% \mathrm{CI}=0.14-0.98$; $\mathrm{P}=0.05)$ among smokers. However, the overall effects showed no significant difference in different genotypes in bladder cancer. These results were also consistently observed in other studies. The distribution of XRCC1 Arg399Gln genotypes in the 15 studies strictly complied with Hardy-Weinberg equilibrium. Our meta-analysis based on these 15 studies revealed no association between the XRCC1 Arg399Gln polymorphism and bladder cancer risk in the comparisons of Gln allele vs Arg allele, (Gln/Gln + Gln/Arg) vs Arg/Arg, Gln/Gln vs (Gln/Arg + Arg/Arg), Gln/Gln vs Arg/Arg, and Gln/Arg vs Arg/Arg.

Relationships between the XRCC1 Arg399Gln polymorphism and cancer development have been observed for several cancers. Kiyohara et al. (2006) and Mattulo et al. (2006) found that the XRCC1 399G/n/Gln genotype was associated with risk of lung cancer. Duell et al. (2001) identified the same genotype to be associated with breast cancer risk in African Americans. However, no relationships between the XRCC1 Arg399Gln polymorphism and bladder cancer have been found in recent studies.

Relationships between genotypes and pathological grade, clinical stage, or prognosis have been reported. Sanyal et al. (2007) indicated that variant allele carriers of the XRCC1 polymorphism showed a lower risk of recurrence (Stage TaG2; P = 0.05) and death (Stage T2 or greater; $\mathrm{P}=0.03$ ) after instillation and radiotherapy compared to non-carriers. Sakano et al. (2006) showed that for patients with bladder cancer after platinum-based chemoradiotherapy, combined genotypes with at least one variant allele in XRCC1 were significantly associated with improved cancer-specific survival compared with the remaining groups. In all included studies, subjects of different nationalities showed different genotype frequencies. However, the different genotypes did not affect the overall results. In the subgroup meta-analysis by ethnicity, no association was observed between the XRCC1 Arg399Gln polymorphism and bladder cancer risk in Caucasian, Mongoloid, and black populations. However, data regarding genotypes in the black population were limited and incomplete. Only Stern et al. (2001) reported detailed data for the genotypes of the black population. Thus, the relationship between the XRCC1 Arg399Gln polymorphism and bladder cancer risk in the black population requires further investigation.

Smoking has been reported to be the most important cause of bladder cancer, and the risk has been shown to be dose-dependent. The relationship between the XRCC1 Arg399Gln polymorphism and bladder cancer risk differed when smoking status was included in the analysis (Burch et al., 1989; Taylor et al., 1998). Shen et al. (2003) reported that the Arg to Gln substitution may provide protection against bladder cancer in heavily smoking subgroups. Stern et al. (2001) observed that a reduction in bladder cancer risk was associated with decreased smoking, which was slightly more pronounced among Gln/Gln subjects. We attempted to reach a definitive conclusion through subgroup analysis of variant status of smoking. However, division of most studies and varying classification criteria of data did not allow for this analysis. 
There were some limitations to our meta-analysis. First, to obtain more reliable results, we strictly compiled data according to the rules of Hardy-Weinberg equilibrium, so that 5 studies were excluded, which may have affected the overall effects of our meta-analysis. Second, we were not able to address sources of heterogeneity existing among studies for each polymorphism. Further subgroup stratifications analysis was not possible because of the limited number of published studies and different classification criteria of the data. In addition, the small sample size was not ideal for detecting small genetic effects. Finally, our systematic review was based on unadjusted data, as the genotype information stratified for the main confounding variables was not available in the original papers; the specific confounding factors adjusted for differed among the studies.

In conclusion, our meta-analysis suggests no association between the XRCC1 Arg399Gln polymorphism and bladder cancer risk. Additional large-scale studies with adequate methodological quality and controls for possible confounding effects should be conducted.

\section{ACKNOWLEDGMENTS}

We appreciate the help of Yili Liu (Department of Urological Surgery, the Fourth Affiliated Hospital of China Medical University, Shenyang, China) for her valuable contributions to the statistical analysis.

\section{REFERENCES}

Abdel-Rahman SZ and El-Zein RA (2000). The 399Gln polymorphism in the DNA repair gene XRCC1 modulates the genotoxic response induced in human lymphocytes by the tobacco-specific nitrosamine NNK. Cancer Lett. 159: 63-71.

Andrew AS, Nelson HH, Kelsey KT, Moore JH, et al. (2006). Concordance of multiple analytical approaches demonstrates a complex relationship between DNA repair gene SNPs, smoking and bladder cancer susceptibility. Carcinogenesis 27: 1030-1037.

Andrew AS, Karagas MR, Nelson HH, Guarrera S, et al. (2008). DNA repair polymorphisms modify bladder cancer risk: a multi-factor analytic strategy. Hum. Hered. 65: 105-118.

Arizono K, Osada Y and Kuroda Y (2008). DNA repair gene hOGG1 codon 326 and XRCC1 codon 399 polymorphisms and bladder cancer risk in a Japanese population. Jpn. J. Clin. Oncol. 38: 186-191.

Broberg K, Bjork J, Paulsson K, Hoglund M, et al. (2005). Constitutional short telomeres are strong genetic susceptibility markers for bladder cancer. Carcinogenesis 26: 1263-1271.

Burch JD, Rohan TE, Howe GR, Risch HA, et al. (1989). Risk of bladder cancer by source and type of tobacco exposure: a case-control study. Int. J. Cancer 44: 622-628.

Campalans A, Marsin S, Nakabeppu Y, O'connor TR, et al. (2005). XRCC1 interactions with multiple DNA glycosylases: a model for its recruitment to base excision repair. DNA Repair 4: 826-835.

Cohen SM, Shirai T and Steineck G (2000). Epidemiology and etiology of premalignant and malignant urothelial changes. Scand. J. Urol. Nephrol. Suppl. 105-115.

Das A, Wiederhold L, Leppard JB, Kedar P, et al. (2006). NEIL2-initiated, APE-independent repair of oxidized bases in DNA: Evidence for a repair complex in human cells. DNA Repair 5: 1439-1448.

Duell EJ, Wiencke JK, Cheng TJ, Varkonyi A, et al. (2000). Polymorphisms in the DNA repair genes XRCC1 and ERCC2 and biomarkers of DNA damage in human blood mononuclear cells. Carcinogenesis 21: 965-971.

Duell EJ, Millikan RC, Pittman GS, Winkel S, et al. (2001). Polymorphisms in the DNA repair gene XRCC1 and breast cancer. Cancer Epidemiol. Biomarkers Prev. 10: 217-222.

Figueroa JD, Malats N, Real FX, Silverman D, et al. (2007). Genetic variation in the base excision repair pathway and bladder cancer risk. Hum. Genet. 121: 233-242.

Fontana L, Bosviel R, Delort L, Guy L, et al. (2008). DNA repair gene ERCC2, XPC, XRCC1, XRCC3 polymorphisms and associations with bladder cancer risk in a French cohort. Anticancer Res. 28: 1853-1856.

Gao W, Romkes M, Zhong S, Nukui T, et al. (2010). Genetic polymorphisms in the DNA repair genes XPD and XRCC1, 
p53 gene mutations and bladder cancer risk. Oncol. Rep. 24: 257-262.

Higgins JP and Thompson SG (2002). Quantifying heterogeneity in a meta-analysis. Stat. Med. 21: 1539-1558.

Huang M, Dinney CP, Lin X, Lin J, et al. (2007). High-order interactions among genetic variants in DNA base excision repair pathway genes and smoking in bladder cancer susceptibility. Cancer Epidemiol. Biomarkers Prev. 16: 84-91.

Karahalil B, Kocabas NA and Ozcelik T (2006). DNA repair gene polymorphisms and bladder cancer susceptibility in a Turkish population. Anticancer Res. 26: 4955-4958.

Kelsey KT, Park S, Nelson HH and Karagas MR (2004). A population-based case-control study of the XRCC1 Arg399Gln polymorphism and susceptibility to bladder cancer. Cancer Epidemiol. Biomarkers Prev. 13: 1337-1341.

Kiyohara C, Takayama K and Nakanishi Y (2006). Association of genetic polymorphisms in the base excision repair pathway with lung cancer risk: a meta-analysis. Lung Cancer 54: 267-283.

Lunn RM, Langlois RG, Hsieh LL, Thompson CL, et al. (1999). XRCC1 polymorphisms: effects on aflatoxin B1-DNA adducts and glycophorin A variant frequency. Cancer Res. 59: 2557-2561.

Masson M, Niedergang C, Schreiber V, Muller S, et al. (1998). XRCC1 is specifically associated with poly (ADP-ribose) polymerase and negatively regulates its activity following DNA damage. Mol. Cell Biol. 18: 3563-3571.

Matullo G, Guarrera S, Carturan S, Peluso M, et al. (2001). DNA repair gene polymorphisms, bulky DNA adducts in white blood cells and bladder cancer in a case-control study. Int. J. Cancer 92: 562-567.

Matullo G, Guarrera S, Sacerdote C, Polidoro S, et al. (2005). Polymorphisms/haplotypes in DNA repair genes and smoking: a bladder cancer case-control study. Cancer Epidemiol. Biomarkers Prev. 14: 2569-2578.

Matullo G, Dunning AM, Guarrera S, Baynes C, et al. (2006). DNA repair polymorphisms and cancer risk in non-smokers in a cohort study. Carcinogenesis 27: 997-1007.

Mittal RD, Mandal RK and Gangwar R (2012). Base excision repair pathway genes polymorphism in prostate and bladder cancer risk in North Indian population. Mech. Ageing Dev. 133: 127-132.

Peters JL, Sutton AJ, Jones DR, Abrams KR, et al. (2006). Comparison of two methods to detect publication bias in metaanalysis. JAMA 295: 676-680.

Sak SC, Barrett JH, Paul AB, Bishop DT, et al. (2007). DNA repair gene XRCC1 polymorphisms and bladder cancer risk. BMC Genet. 8: 13.

Sakano S, Wada T, Matsumoto H, Sugiyama S, et al. (2006). Single nucleotide polymorphisms in DNA repair genes might be prognostic factors in muscle-invasive bladder cancer patients treated with chemoradiotherapy. Br. J. Cancer 95: 561-570.

Sanyal S, Festa F, Sakano S, Zhang Z, et al. (2004). Polymorphisms in DNA repair and metabolic genes in bladder cancer. Carcinogenesis 25: 729-734.

Sanyal S, De Verdier PJ, Steineck G, Larsson P, et al. (2007). Polymorphisms in XPD, XPC and the risk of death in patients with urinary bladder neoplasms. Acta Oncol. 46: 31-41.

Shen M, Hung RJ, Brennan P, Malaveille C, et al. (2003). Polymorphisms of the DNA repair genes XRCC1, XRCC3, $\mathrm{XPD}$, interaction with environmental exposures, and bladder cancer risk in a case-control study in northern Italy. Canc. Epidemiol. Biomarkers Prev. 12: 1234-1240.

Siegel R, Naishadham D and Jemal A (2012). Cancer statistics, 2012. CA Cancer J. Clin. 62: 10-29.

Steineck G, Wiholm BE and Gerhardsson de Verdier M (1995). Acetaminophen, some other drugs, some diseases and the risk of transitional cell carcinoma. A population-based case-control study. Acta Oncol. 34: 741-748.

Stern MC, Umbach DM, van Gils CH, Lunn RM, et al. (2001). DNA repair gene XRCC1 polymorphisms, smoking, and bladder cancer risk. Cancer Epidemiol. Biomarkers Prev. 10: 125-131.

Taylor JA, Umbach DM, Stephens E, Castranio T, et al. (1998). The role of N-acetylation polymorphisms in smokingassociated bladder cancer: evidence of a gene-gene-exposure three-way interaction. Cancer Res. 58: 3603-3610.

Vidal AE, Boiteux S, Hickson ID and Radicella JP (2001). XRCC1 coordinates the initial and late stages of DNA abasic site repair through protein-protein interactions. EMBO J. 20: 6530-6539.

Viechtbauer W (2007). Confidence intervals for the amount of heterogeneity in meta-analysis. Stat.Med. 26: 37-52.

Wang M, Qin C, Zhu J, Yuan L, et al. (2010). Genetic variants of XRCC1, APE1, and ADPRT genes and risk of bladder cancer. DNA Cell Biol. 29: 303-311.

Wen H, Ding Q, Fang ZJ, Xia GW, et al. (2009). Population study of genetic polymorphisms and superficial bladder cancer risk in Han-Chinese smokers in Shanghai. Int. Urol. Nephrol. 41: 855-864.

Zhi Y, Yu J, Liu Y, Wei Q, et al. (2012). Interaction between polymorphisms of DNA repair genes significantly modulated bladder cancer risk. Int. J. Med. Sci. 9: 498-505.

Zintzaras E and Ioannidis JP (2005). Heterogeneity testing in meta-analysis of genome searches. Genet. Epidemiol. 28 : 123-137.

Genetics and Molecular Research 13 (4): 9976-9985 (2014) 